\title{
THE CYCLIC HYDROBORATION OF DIENES-A SIMPLE CONVENIENT ROUTE TO HETEROCYCLIC ORGANOBORANES
}

\author{
H. C. Brown and E. Negishi
}

Department of Chemistry, Purdue University, Lafayette. Indiana 47907, USA

\begin{abstract}
A systematic study of the cyclic hydroboration of a representative series of dienes with borane in tetrahydrofuran as well as with thexylborane is undertaken.

The elucidation of the structures of the major products derived from 1.3butadiene and borane and of the mechanistic paths leading to their formulation has been accomplished. Several new analytical techniques, such as gas-liquid partition chromatography examination of $B$-methoxyboracyclanes and the carbonylation-oxidation of organoboranes, are introduced.

By employing these new techniques, the extent of cyclic hydroboration of a representative series of dienes with borane is determined. Based on the findings in this study, simple syntheses of representative bisboracyclanes. such as bisborinane and 9-borabicyclo[3.3.1] nonane, are accomplished. The hydroboration of olefins with these bisboracyclanes represents a convenient and general procedure for the preparation of the corresponding $B$-alkylboracyclanes.

The cyclic hydroboration of dienes with thexylborane in many cases provides the corresponding $B$-thexylboracyclanes in high yields. Finally. the usefulness of $B$-alkylboracyclanes as valuable intermediates in the organic synthesis via hydroboration is briefly discussed.
\end{abstract}

\section{INTRODUCTION}

Since the discovery of hydroboration in $1956^{1}$, a number of publications have appeared dealing with the hydroboration of dienes and polyenes. Our earlier studies ${ }^{2-6}$ on the hydroboration of dienes were primarily concerned with the syntheses of diols and enols. The structures of the organoborane intermediates were not of major concern and, therefore, were not investigated in detail.

The carbonylation of trialkylboranes ${ }^{7}$ has provided for the first time a means of converting trialkylboranes into the corresponding carbon compounds while retaining all of the original structural features of the organoborane. A few of the more interesting examples involving cyclic organoboranes are shown by Eqn 1-3.<smiles></smiles>

H

I

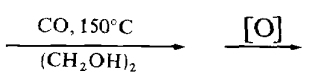

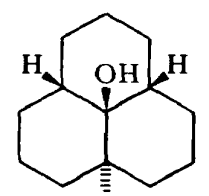

$\overline{\mathrm{H}}$

II $\left(70^{\circ} \%\right.$ vield) 
<smiles>C1CCC2CCCCB2C1</smiles>

III<smiles>C1CCC(B2C3CC4CC2CC(C3)C42CC2)CC1</smiles>

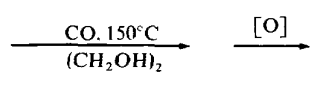

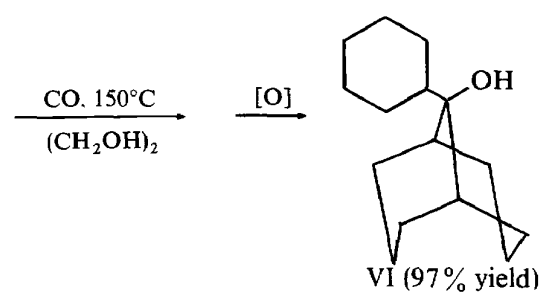<smiles>OC12CCCCC1CCCC2</smiles>

IV $(89 \%$ yield $)$ predominantly cis

$(3)^{10}$

Alternatively, the carbonylation of cyclic organoboranes can be controlled to provide the corresponding cyclic ketones (Eqn 4 and 5).

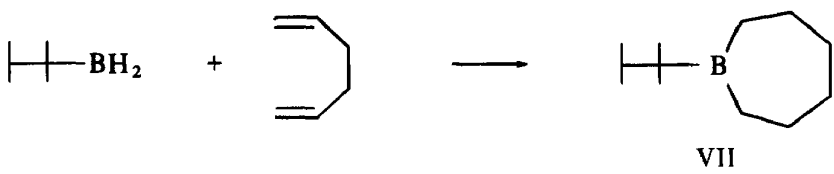

$$
\frac{\mathrm{CO} .50^{\circ} \mathrm{C}}{\mathrm{H}_{2} \mathrm{O}} \stackrel{[\mathrm{O}]}{\longrightarrow}
$$

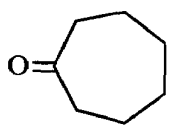

VIII $(62 \%$ vield $)$
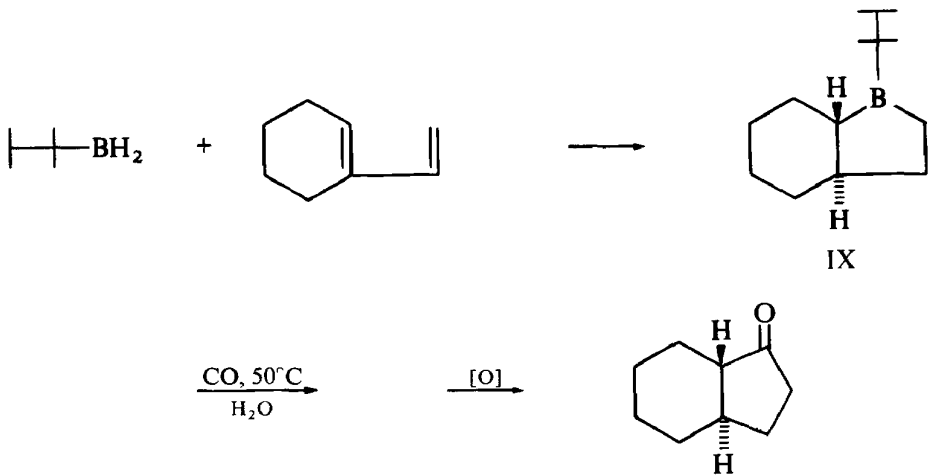

$\mathrm{X}\left(66^{\circ} \%\right.$ yjeld $)$

Such synthetic possibilities have made it desirable to be able to synthesize organoboranes of known structures. Consequently, it became important to learn how to control the hydroboration of dienes and polyenes with borane (or diborane) and substituted boranes in order to produce cyclic and polycyclic compounds with known structures easily and at will. 
Molecular rearrangements have not yet been observed in the reaction of organoboranes with carbon monoxide. Consequently, it appears promising that the carbonylation of cyclic organoboranes should provide a reliable means of determining the precise structures of such organoboranes, making available a powerful analytical tool applicable to the study of the cyclic hydroboration of dienes and polyenest.

Accordingly, we decided to undertake a systematic investigation of the cyclic hydroboration of dienes and polyenes with the following objectives: to understand exactly what occurs in the hydroboration of dienes and polyenes, and to learn how to control the reaction to produce desirable cyclic compounds.

\section{THE CASE OF 1,3-BUTADIENE}

Prior to our studies on cyclic hydroboration, a considerable number of papers, including the extensive review articles by Köster ${ }^{15,16}$, had been published. Unfortunately, however, these earlier works are often contradictory and quite confusing. Let us consider the situation with respect to the simplest conjugated diene, 1,3-butadiene.

The hydroboration of 1,3-butadiene with borane in tetrahydrofuran (THF) in a $1: 1$ molar ratio produces a polymeric material ${ }^{4}$. The remaining boron-hydrogen bonds exhibit the usual reactivity of such bonds and undergo rapid hydrolysis and methanolysis at $0^{\circ} \mathrm{C}$. However, distillation of the $1: 1$ polymeric product produces in high yield a $1: 1$ dimer of unusual stability. Thus, the compound does not react either with water or with olefins at appreciable rates below $100^{\circ} \mathrm{C}$. The compound was originally prepared by Köster ${ }^{17}$, and he proposed its structure to be that of bisborolane (XIII).

$\dagger$ It was the results of carbonylation experiments ${ }^{8,13}$ that enabled us to revise the original structural assignment of the two isomeric perhydro-9-boraphenalenes (I and XI) ${ }^{14}$.

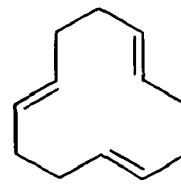<smiles>C1C[C@H]2CC[C@H]3CCC[C@@H]2[C@@H](C1)C3</smiles>

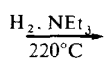<smiles></smiles><smiles>CC1(C)[C@@H]2CCC[C@@H]3CCC[C@@]1(C)[C@@H]3CCC2</smiles>

$\overline{\mathrm{H}}$
XI

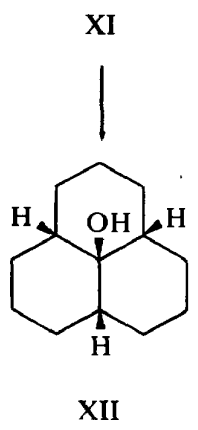

(6) 
<smiles></smiles>

XIII<smiles></smiles>

XIV

However, the bisborolane structure did not appear to be compatible with these unusual properties. Therefore, we proposed the alternative structure, 1,6-diboracyclodecane (XIV) ${ }^{4}$. The highly unusual characteristics of the compound are readily understood in terms of the 1,6-diboracyclodecane, where the transannularly bridged structure could greatly stabilize the boron-hydrogen bridge and render this moiety highly inert toward reagents which usually attack it with ease. Our subsequent study ${ }^{18}$ enabled us to conclude that XIV was indeed the structure of the 1:1 stable dimer. Thus, protonolysis of the 1:1 stable dimer formed 1,4-butanediboronic acid. Clearly, the result is compatible with XIV but not with XIII.

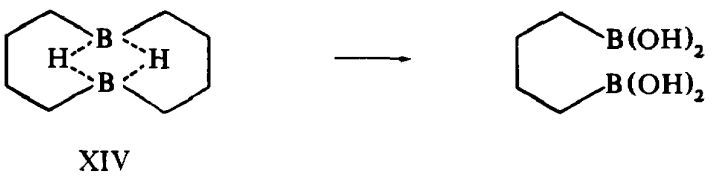

This conclusion was further confirmed by Young and Shore ${ }^{19}$ by the molecular weight determination of amine complexes of the stable dimer. Similarly, Köster's assignment ${ }^{15-17}$ of XV to a material obtained from XIV and diborane was questioned by Young and Shore ${ }^{19}$, who believe that Köster prepared XVI rather than XV.<smiles>BP1CCCC1</smiles>

XV<smiles></smiles>

XVI

Köster ${ }^{20}$ and Saegebarth ${ }^{21}$ reported independently that the hydroboration of 1,3-butadiene with diborane or triethylamineborane yields as the $3: 2$ product 1,4-bis(1'-borolyl)butane (XVII). On the other hand, Mikhailov ${ }^{22}$ and Zakharkin ${ }^{23}$ reported that in this reaction they obtained a mixture consisting largely of XVII and XVIII. Their conclusions were mostly based

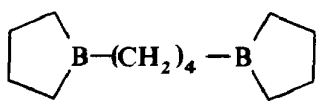

XVII<smiles>CC(C)B1CCCC1</smiles>

XVIII 
on the identification of the products formed in the oxidation of the distilled product. Indeed, their results are far more consistent with our early identification of the diols from the hydroboration-oxidation of 1,3-butadiene ${ }^{4}$ than are those of Köster and Saegebarth. However, none of these earlier workers considered the alternative structures XIX and XX.

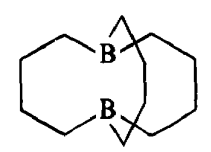

XIX

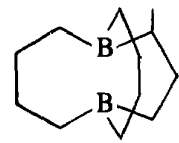

$\mathrm{XX}$

It is quite clear that to rely entirely upon identification of the oxidation products for characterization of organoboranes could be misleading. Accordingly, we decided to undertake an investigation of the structures of the $3: 2$ products utilizing less ambiguous methods.

Diborane is highly soluble in tetrahydrofuran and such solutions are convenient for hydroborations. Consequently, we utilized the hydroboration of dienes with borane in tetrahydrofuran in these studies.

In addition to gas-liquid partition chromatography (g.l.p.c.) identification of the oxidation products, we employed the following techniques in the structural elucidation of these cyclic organoboranes: (1) g.l.p.c. examination of the organoboranes; (2) p.m.r. examination of the organoboranes; (3) carbonylation-oxidation of the organoboranes; and (4) independent syntheses of the organoboranes. Application of these newer techniques permitted us to reach the following conclusions ${ }^{24}$ :

(1) The 3:2 products consist mainly of a mixture of dumb-bell shaped compounds XVII and XVIII in the ratio of approximately $30: 70$. No evidence for the formation of the cage compounds XIX and XX was obtained. Thus, our results parallel most closely those obtained by Zakharkin ${ }^{23}$.

(2) The thermal treatment at isomerizing temperatures $\left(140^{\circ}-170^{\circ} \mathrm{C}\right)$ of the initial $3: 2$ product produces largely a mixture of XVII and a novel species XXI in the ratio of approximately 25:75 (Eqn 8).<smiles>C1CCB(CCP2CCCC2)C1</smiles>

XVII

$+$

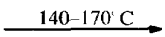

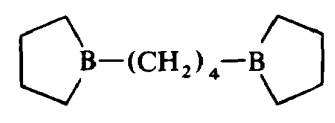

XVII

$+$<smiles>CC(C)B1CCCC1</smiles>

XVIII

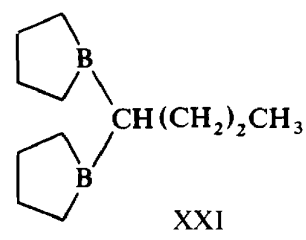


These results of the thermal treatment are considerably different from those reported by Zakharkin ${ }^{23}$. He reported that the thermal treatment at $160^{\circ} \mathrm{C}$ of the 3:2 product converted 76 per cent of the product into XVII. No mention was made of the formation of XXI. The failure to detect XXI by Zakharkin ${ }^{23}$ again points to the danger of relying entirely on the identification of the oxidation products for characterization of organoborane.

We then turned our attention to the elucidation of the initial 1:1 polymeric product with normal properties of dialkylboranes. The hydroboration of 1,3-butadiene by the addition of the stoichiometric quantity of borane in THF is largely complete as soon as the addition of borane is over. Therefore, the hydroboration of 1,3-butadiene with borane in a 1:1 molar ratio should largely proceed through the formation of the $3: 2$ dumb-bell compounds. Our recent study on the 1:1 polymeric product ${ }^{25}$ permits us to formulate its structure as shown by XXIII and to depict its formation as shown by Eqn 9 .

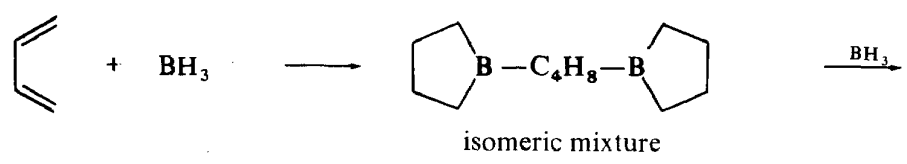<smiles></smiles>

XXII

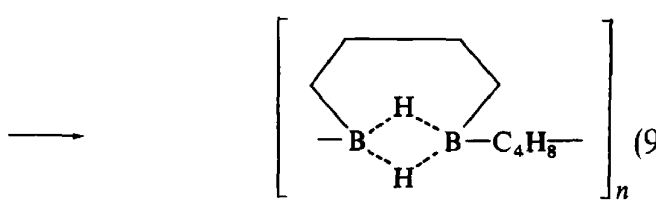

XXIII

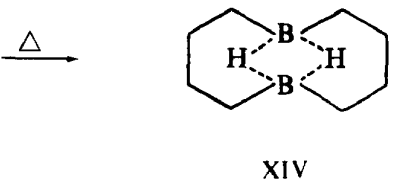

This conclusion was strongly supported by the finding that borane readily opens the borolane ring moiety of $B$-alkylborolanes ${ }^{26}$ (Eqn 10). Even the terminal B-H bond of XXII is reactive enough to open the borolane ring slowly. ${ }^{25}$ This leads to the formation of the polymer XXIII.

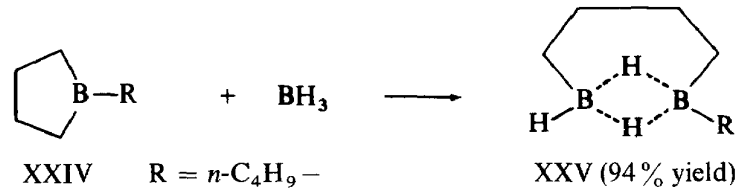

Thus, the elucidation of the structures of the major products derived from the hydroboration of 1,3-butadiene under various reaction conditions and of the mechanistic paths leading to their formation has been essentially completed. 


\section{HYDROBORATION OF DIENES WITH BORANE IN TETRAHYDROFURAN IN THE MOLAR RATIO OF 1:1}

In the study of the hydroboration of 1,3-butadiene, we found that g.l.p.c. examination of the methanolysed product of a hydroboration mixture provided a convenient means of analysing the actual amount of boracyclanes present in the hydroboration mixture ${ }^{25}$. Accordingly, we decided to undertake a systematic study with a representative series of dienes. In this study a diene was hydroborated by its addition to an equimolar quantity of borane in THF. The reaction mixture was stirred at $25^{\circ} \mathrm{C}$ and examined periodically by the g.l.p.c. analysis after methanolysis as well as by i.r., active hydride analysis and g.l.p.c. analysis of the oxidation products.

The results are summarized in Table $1^{27}$.

Table 1. Cyclic hydroboration of dienes with borane in THF in the molar ratio of $1: 1$

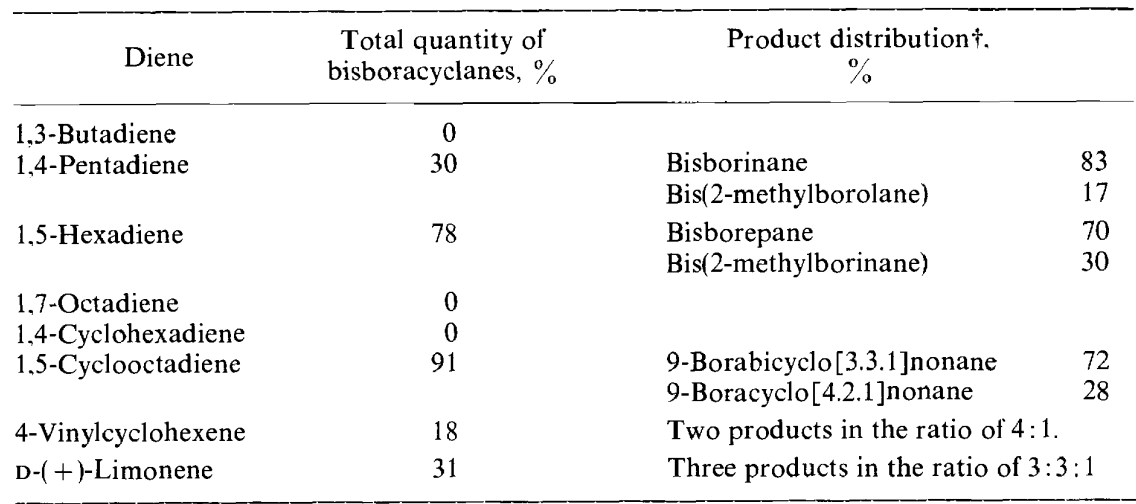

† Borolane : boracyclopentanc; borinane : boracyclohexane; borepane : boracycloheptane.

In the interpretation of these results, we have found that the alkyl-hydrogen exchange reaction, which almost invariably accompanies the hydroboration of dienes with borane in a $1: 1$ molar ratio, plays an important role. We have already explained why the hydroboration of 1,3-butadiene in a 1:1 molar ratio does not produce cyclic species in any detectable quantities, despite the fact that the hydroboration in a $3: 2$ molar ratio gives the $3: 2$ dumb-bell compounds in high yield. The facile opening of the borolane ring with borane was the key to understanding (Eqn 10).

In marked contrast with the reaction of $B$-alkylborolanes with borane, the reaction of $B$-alkylborinanes with borane does not involve an opening of the borinane ring. Instead, the alkyl group migrates to the borane moiety ${ }^{26}$ (Eqn 11).

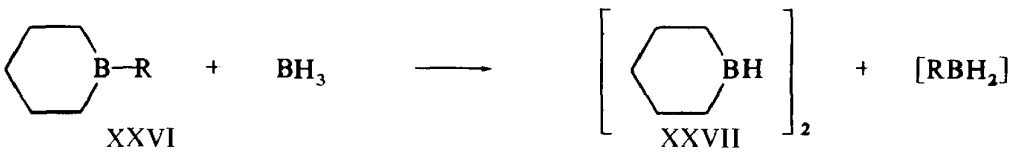

Thus, the order of reactivity of various types of $\mathrm{B}-\mathrm{C}$ bonds toward borane may be summarized as follows. 


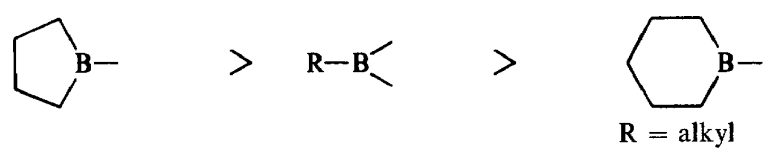

These findings appear to offer a ready interpretation in many other cases of hydroboration of dienes as well.

The hydroboration of 1,4-pentadiene with borane in the stoichiometric ratio produces in high yield $(\sim 70$ per cent $)$ a mixture of at least six $3: 2$ dumb-bell compounds containing the following structural moieties ${ }^{28}$ :<smiles>CCCCCCCB1CCCC1C</smiles>

XXVIII

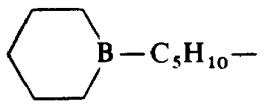

XXIX

Therefore, based on the findings with the reaction of $B$-alkylboracyclanes with borane, it seems reasonable to observe bisboracyclanes in only 30 per cent yield. The $1: 1$ product must contain the moiety shown by XXX, which could arise from the reaction of XXVIII with borane, in addition to bisborinane.

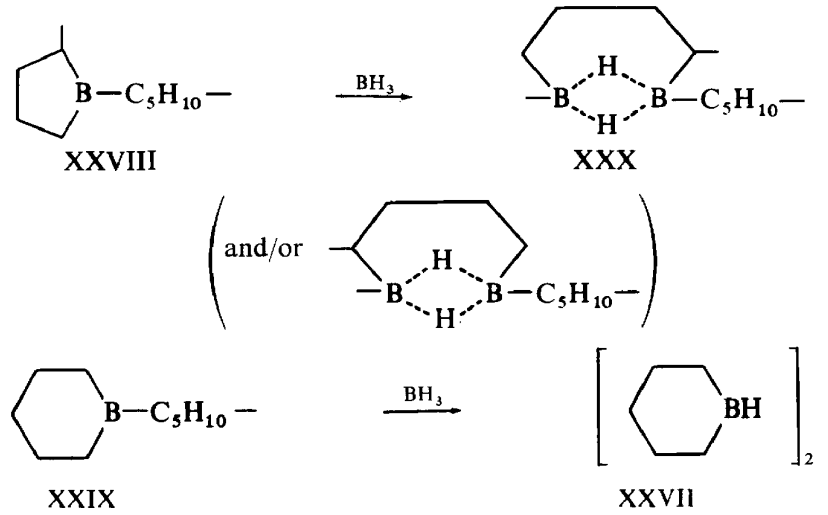

On heating the initially formed $1: 1$ product, bisborinane and a $1: 1$ stable dimer XXXI were formed in approximately 45 and 50 per cent yields, respectively ${ }^{28}$ (Eqn 14).

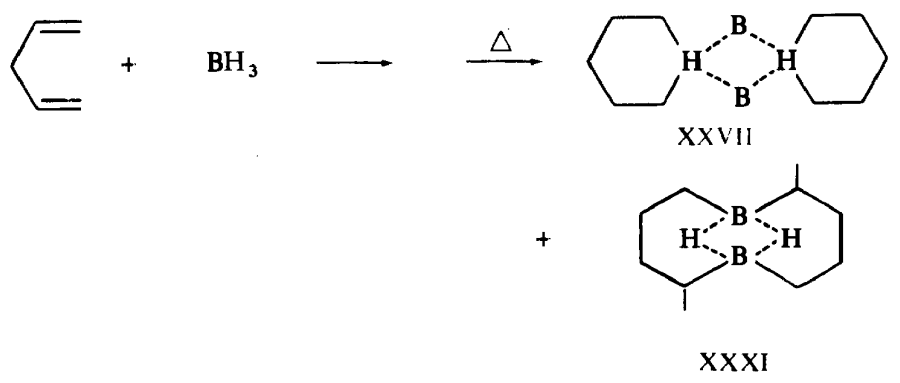


Since the hydroboration of 1,4-pentadiene with borane yields, after oxidation, 1,5- and 1,4-pentanediols in the molar ratio of $45: 55$, essentially all of the pentamethylene and 1-methyltetramethylene moieties must have been converted cleanly to bisborinane and XXXI, respectively. We have not so far been able to interconvert bisborinane and XXXI. Therefore, it is not clear which of the two is thermally more stable.

The hydroboration of 1,5-hexadiene provides bisborepane (XXXII) and bis(2-methylborinane) (XXXIII) in 78 per cent yield in the ratio 70:30 (Eqn $15)$.

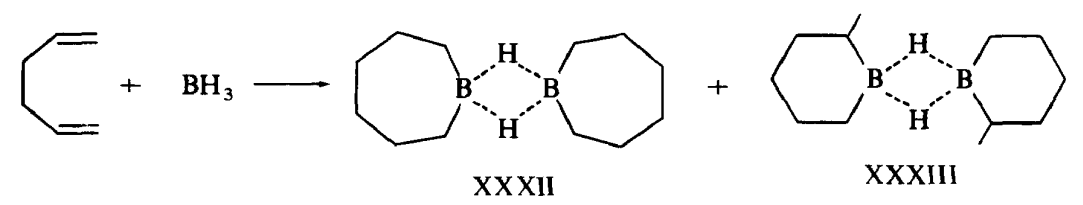

When the product was analysed by g.l.p.c. immediately after the addition of 1,5-hexadiene, the overall yield of XXXII and XXXIII was only 15 per cent, in spite of the fact that the hydroboration of 1,5-hexadiene was essentially complete. The yield of 78 per cent mentioned above was realized six hours later. Therefore, the alkyl-hydride exchange reaction, such as shown by Eqn 16 and 17, must be involved in this case also.

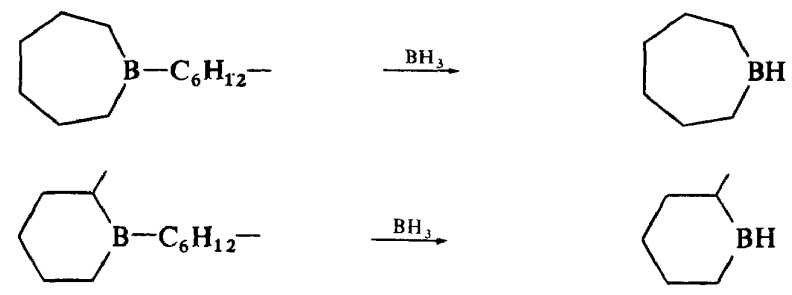

We have not so far observed the formation of boracyclononane in any detectable quantity. The hydroboration of 1,7-octadiene yields a gelatinous material which is largely insoluble in ethereal solvents such as THF. In view of the highly labile nature of organoboranes, however, it seems likely that distillation of such an apparently polymeric product at low temperature and pressure might yield desirable volatile products.

We know very little about exactly what occurs in the hydroboration of 1,4-cyclohexadiene. However, under the usual hydroboration conditions, the corresponding bicyclic boranes XXXIV and XXXV do not appear to be formed in any detectable quantities.

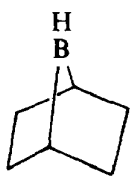

XXXIV

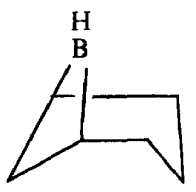

XXXV 
On the other hand, the hydroboration of 1,5-cyclooctadiene yields cleanly and quantitatively a $72: 28$ mixture of 9-borabicyclo[3.3.1]nonane (XXXVI) and 9-borabicyclo[4.2.1]nonane $(\mathrm{XXXVII})^{29}$. The latter can be readily isomerized to XXXVI at $65^{\circ} \mathrm{C}$. Thus, hydroboration followed by heating of the resultant hydroboration mixture in THF under reflux for one hour provides XXXVI in quantitative yield ${ }^{28}$ (Eqn 18).

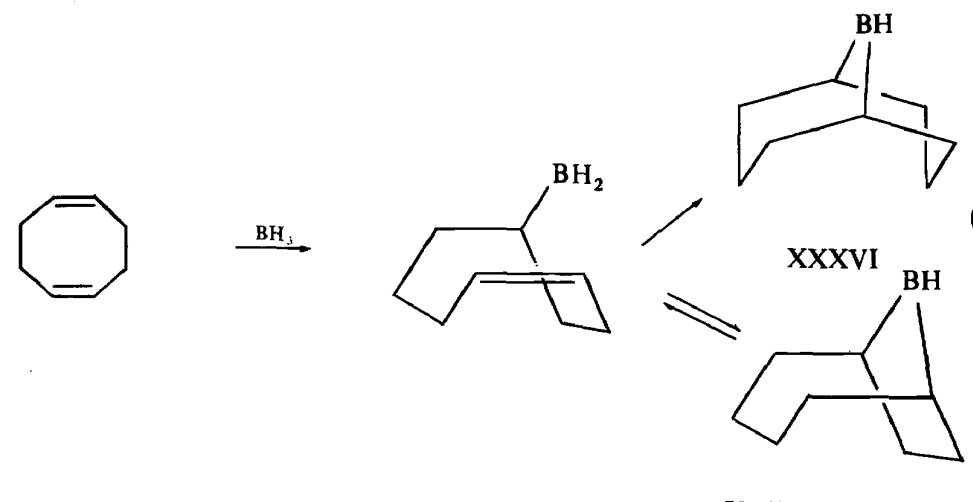

XXXVII

We are currently investigating the hydroboration of 4-vinylcyclohexene (XXXVIII) and D- $(+)$-limonene (XXXIX) ${ }^{30}$.<smiles>C=CC1CC=CCC1</smiles>

XXXVIII<smiles>C=C(C)C1CC=C(C)CC1</smiles>

XXXIX

At this stage, we are slightly puzzled by the relatively low yields of cyclic species in the initial hydroboration stage. The major products appear to be $\mathrm{XL}$ and XLI.

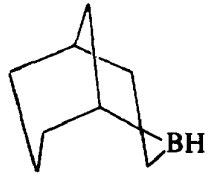

XL

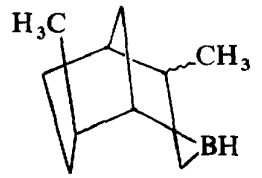

XLI

\section{THE CYCLIC HYDROBORATION OF DIENES WITH THEXYLBORANE}

2,3-Dimethyl-2-butylborane (thexylborane) (XLII) is a readily available monoalkylborane ${ }^{6,31,32}$ (Eqn 19). 
<smiles>CC(C)=C(C)C</smiles>

XLII

Since it is difunctional, the hydroboration of olefins with this reagent in favourable cases should provide cleanly the corresponding $B$-thexylboracyclanes without the complication observed in the hydroboration of dienes with borane. Therefore, thexylborane should serve as a model hydroborating agent for the study of the cyclic hydroboration of dienes. Moreover, as was mentioned earlier, $B$-thexylboracyclanes can be useful intermediates in the cyclic ketone synthesis (Eqn 4 and 5). Accordingly, we decided to investigate the cyclic hydroboration of dienes with thexylborane in detail $\dagger$.

In this study a diene was hydroborated by the addition of an equimolar quantity of thexylborane at $0^{\circ} \mathrm{C}$. At the completion of hydroboration, the reaction mixture was analysed by g.l.p.c. on a short SE-30 column. It has been established that under carefully selected conditions g.l.p.c. examination offers a highly convenient means of determining the exact quantities of $B$ thexylboracyclanes in most cases $^{36}$.

In this manner, we have found that the hydroboration of 1,3-butadiene with thexylborane is only 17 per cent cyclic, whereas that of 2,3-dimethyl1,3-butadiene is a simple, nearly quantitative cyclization (Eqn 23 and 24).

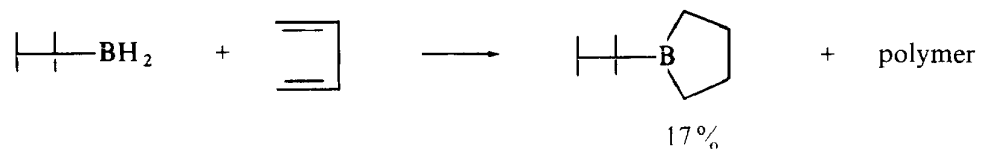

$\dagger$ Prior to our work with thexylborane, the hydroboration of dienes with phenylborane ${ }^{33}$, trimethylamine- $t$-butylborane ${ }^{34}$, and chloroborane ${ }^{35}$ had been reported (Eqn 20-22).

$\left\lceil-\mathrm{BH}_{2}\right.$

$+\mathrm{BH}_{2} \cdot \mathrm{NMe}_{3}$

$+$
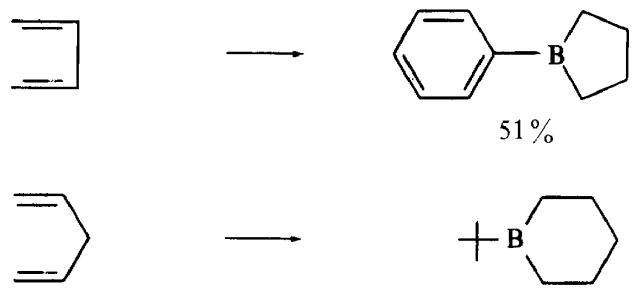

$51 \%$

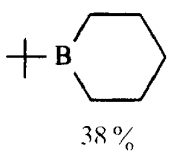

$\mathrm{ClBH}_{2}$

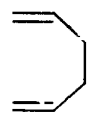

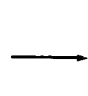

$69 \%$

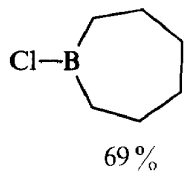




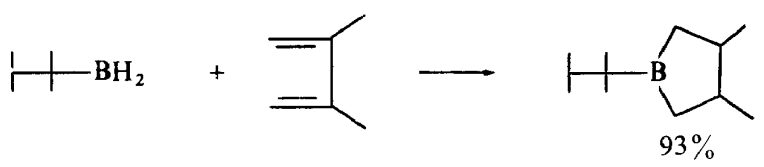

The reaction of 1,4-pentadiene is also highly cyclic, yielding predominantly a five-membered ring (Eqn 25).

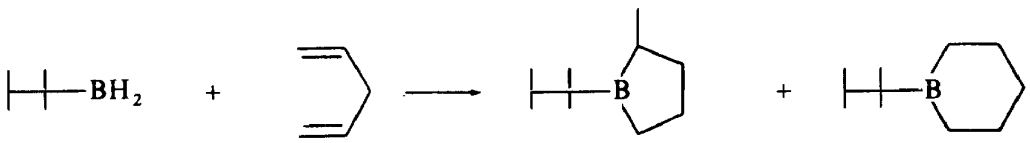

$81 \% .70: 30$

There appears to exist a strong preference for the formation of a fivemembered ring in the competitive formation of five- and six-membered boracyclanes. On the other hand, in the competitive formation of six- and seven-membered boracyclanes, neither appears strongly favoured over the other, and the usual directive effect appears to control the product distribution. Thus, the reaction of 1,5-hexadiene yields a 90:2:8 mixture of XLIII, XLIV, and XLV in 85 per cent overall yield (Eqn 26).
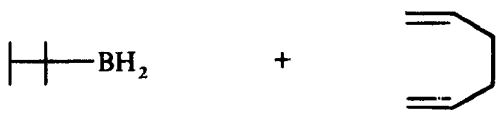

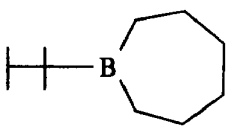

XLIII

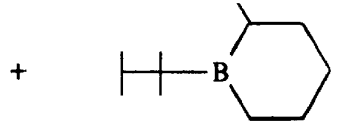

XLIV

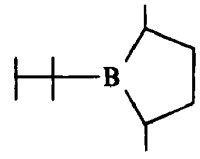

XLV

Based on these observations, it is not unexpected to find a $78: 22$ ratio of XLVI and XLVII as the initial products of hydroboration of 1,5-cyclooctadiene, since the formation of a five-membered boracyclane should be favoured over that of a six-membered ring.
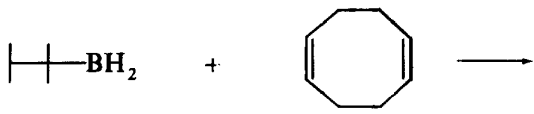
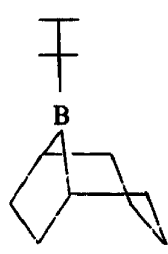

XLVI

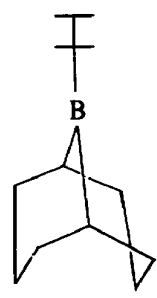

XLVII

$(78: 22)$ 
In general, $B$-thexylboracyclanes can be distilled without noticeable isomerization of either the thexyl group or the ring moiety. However, distillation of the mixture of XLVI and XLVII resulted in the complete isomerization of XLVI to XLVII under the distillation conditions.

These $B$-thexylboracyclanes were subjected to the carbonylation-oxidation reaction to provide the corresponding cyclic ketones ${ }^{11,12} \dot{\uparrow}$.

The cyclic hydroboration of $\mathrm{D}-(+)$-limonene with thexylborane followed by distillation provides XLVIII in 72 per cent yield (Eqn 28).
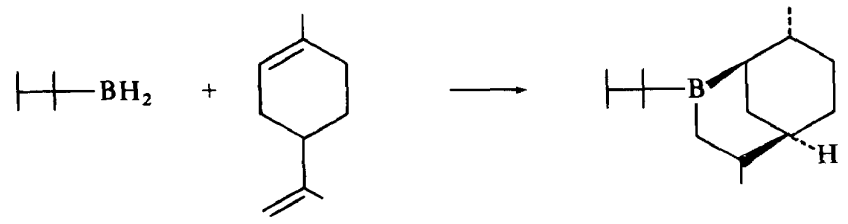

\section{XLVIII}

Its oxidation yielded the isomeric $m$-cis-diols XLIX as the only product. On the other hand, protonolysis of XLVIII followed by oxidation provides a stereospecific synthesis of essentially pure $\mathrm{D}-(-)$-carvomenthol $(\mathrm{L})^{37}$ (Eqn 29).
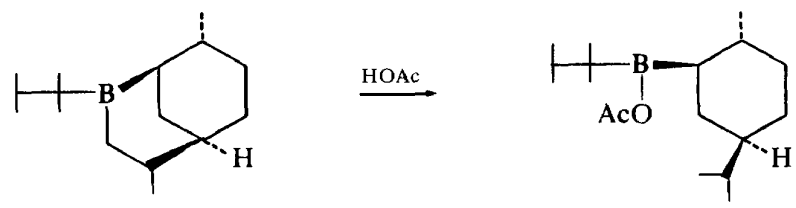

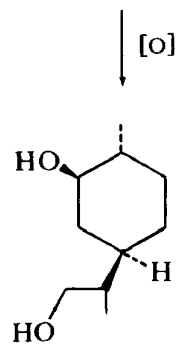

XLIX
HOAC
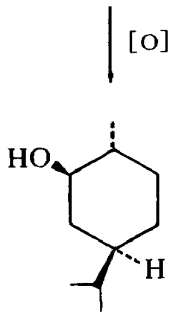

$\mathbf{L}$

Although we have not carried out detailed investigations, our preliminary study ${ }^{37,38}$ indicates that the hydroboration of 1,7-octadiene or 1,4-cyclohexadiene with thexylborane does not involve cyclization to any significant extent.

$\dagger$ The carbonylation of $B$-thexyl-9-BBN was accompanied by the entire isomerization of the thexyl group ${ }^{10}$. 


\section{BISBORACYCLANES AND B-ALKYLBORACYCLANES}

We have now gained a considerable amount of knowledge of the mechanisms involved in the hydroboration of various dienes. However, one of our objectives was to learn how to synthesize $B$-alkylboracyclanes with known structures. We have demonstrated in the previous section that certain $B$ alkylboracyclanes, such as $B$-thexylboracyclanes, can be readily obtained in high yields by the cyclic hydroboration of appropriate dienes with appropriate mono-substituted boranes. Unfortunately, at present only a limited number of mono-substituted boranes are readily available.

An alternative and perhaps more desirable route would be the synthesis of $B$-alkylboracyclanes via bisboracyclanes. Our efforts in this area have been highly successful, and the results will be discussed in this section.

\section{Bisborolanes and $B$-alkylborolanes}

As was discussed earlier, it is now certain that the stable 1:1 dimer derived from 1,3-butadiene and borane is 1,6-diboracyclodecane (XIV) rather than bisborolane (XIII). Likewise, LI and LII reported by Köster ${ }^{15,16}$ should be formulated as LIII and LIV, respectively.<smiles>CCCP1B(PC2CCC(C)C2)CCC1C</smiles>

LI<smiles></smiles>

LIII

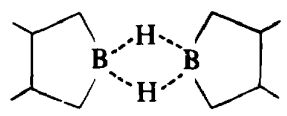

LII

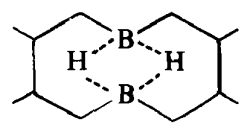

LIV

The first indication that bisborolane might possess the normal properties of a dialkylborane (or tetraalkyldiborane) was obtained in the reduction of $B$-methoxyborolane with lithium aluminium hydride in the presence of olefins $^{39}$ (Eqn 30$)$.<smiles>C1CCB(OCC2CCC2)C1</smiles><smiles>[R]B1CCCC1</smiles>

In this manner $B$ - $(n$-butyl)borolane and $B$-cyclopentylborolane were obtained in 56 and 60 per cent yields, respectively. However, when the reduction was carried out in the absence of olefins followed one hour later by the addition of olefins, the uptake of olefins was quite low. Evidently, bisborolane was formed in this reaction as an unstable intermediate. Clarification of the exact physical and chemical characteristics of bisborolane requires further investigation $^{40}$. 

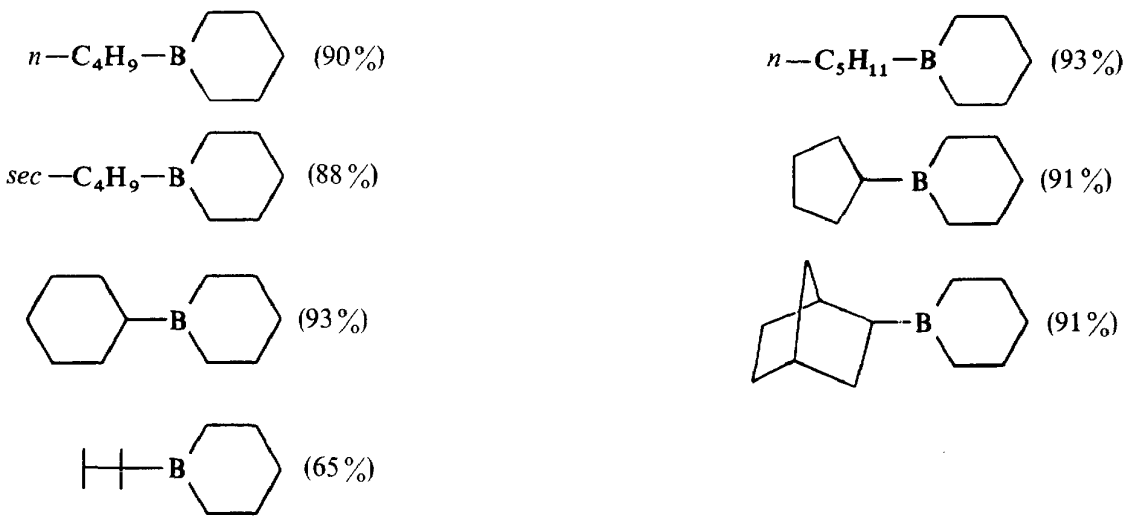

The synthesis of bis(3,5-dimethyl)borinanef (3,5-DMB-6) (LVI) proved to be much simpler than that of the parent compound XXVII. The cyclic hydroboration of 2,4-dimethyl-1,4-pentadiene with borane in THF followed by heating under reflux $\left(\sim 70^{\circ} \mathrm{C}\right)$ for one hour produces $3,5-\mathrm{DMB}-6$ in 94 per cent yield ${ }^{42}$ (Eqn 35).

2
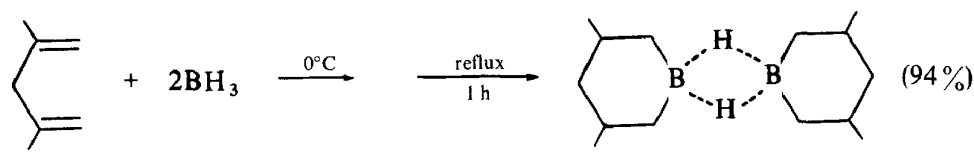

LVI

Like bisborinane, 3,5-DMB-6 is a highly selective hydroborating agent, allowing quantitative conversion of olefins into the corresponding B-alkyl3,5-DMB-6.
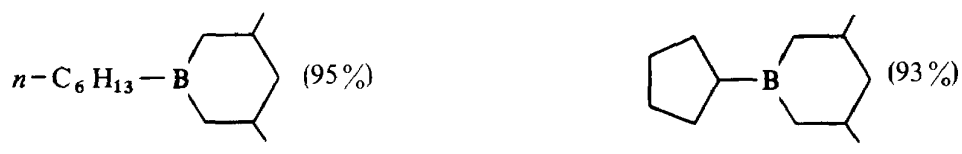

It should be pointed out that the $B$-alkylborinanes and $B$-alkyl-3,5-DMB-6 are applicable as highly useful intermediates in various reactions of organoboranes $^{43}$ (Eqn 36 and 37).

$\dagger$ The compound was first obtained by Köster ${ }^{15}$ by the hydroboration of 2,4-dimethyl-1,3pentadiene with a certain dialkylborane followed by thermal isomerization and treatment with diborane.

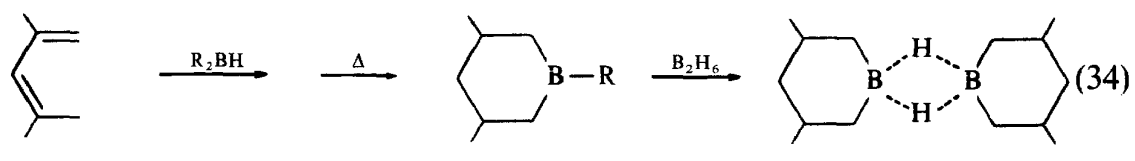



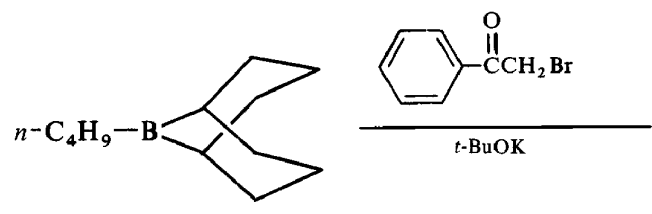

$t-\mathrm{BuOK}$

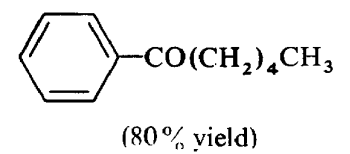

$(80 \%$ vield $)$

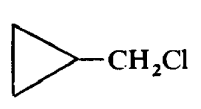

( $81 \%$ yield)

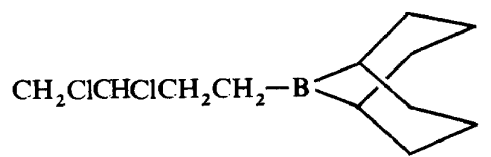

$\mathrm{OH}^{-}$

\section{CONCLUSION}

In the past few years, we have gained a considerable amount of knowledge as to the mechanisms involved in the hydroboration of dienes and polyenes, which has clarified some of the apparent puzzles of the past. In many cases, the hydroboration of dienes and polyenes is not a straightforward reaction and does not readily provide a single product. Nevertheless, we have been quite successful in learning how to control the reaction to obtain the desired products in high yields.

Perhaps more importantly, these cyclic organoboranes have proved to be very useful intermediates in various reactions involving organoboranes.

Obviously, much more work needs to be carried out before we will be able to synthesize cyclic organoboranes of known structures at will. We are actively engaged in studies directed toward such a goal.

It is a pleasure to acknowledge the assistance of Grant GM-10937 from the National Institutes of Health and of Grant DA 31-124 ARO(D) 453 from the U.S. Army Office (Durham).

\section{REFERENCES}

1 H. C. Brown and B. C. Subba Rao. J. Am. Chem. Soc. 78, 5694 (1956).

2 H. C. Brown and G. Zweifel. J. Am. Chem. Soc. 81, 5832 (1959).

${ }^{3}$ H. C. Brown and G. Zweifel. J. Am. Chem. Soc. 82, 3222 (1960).

${ }^{4}$ G. Zweifel, K. Nagase and H. C. Brown. J. Am. Chem. Soc. 84. 183, 190 (1962).

5 G. Zweifel and H. C. Brown. J. Am. Chem. Soc. 85, 2066 (1963).

${ }^{6}$ H. C. Brown. Hydroboration W. A. Benjamin: New York (1962).

7 H. C. Brown. Accounts Chem. Res. 2, 65 (1969).

8 H. C. Brown and E. Negishi. J. Am. Chem. Soc. 89, 5478 (1967).

9 H. C. Brown and E. Negishi. J. Am. Chem. Soc. 91, 1224 (1969).

10 E. F. Knights and H. C. Brown. J. Am. Chem. Soc., 90, 5283 (1968).

11 H. C. Brown and E. Negishi. J. Am. Chem. Soc. 89, 5477 (1967).

12 H. C. Brown and E. Negishi. Chem. Commun. 594 (1968).

13 H. C. Brown and W. C. Dickason. J. Am. Chem. Soc. 91, 1226 (1969).

14 G. W. Rotermund and R. Köster. Justus Liebigs Ann. Chem. 686, 153 (1965).

15 R. Köster. Advan. Organometal. Chem. 2, 257 (1964).

16 R. Köster. Progress in Boron Chemistry (Eds H. Steinberg and A. L. McCloskey), Vol. 1, p289. Pergamon: Oxford (1964).

17 R. Köster. Angew. Chem. 72, 626 (1960). 


\section{THE CYCLIC HYDROBORATION OF DIENES}

18 E. Breuer and H. C. Brown. J. Am. Chem. Soc. 91, 4164 (1969);

E. Breuer and H. C. Brown. Israel J. Chem. 2238 (1964).

19 D. E. Young and S. G. Shore. J. Am. Chem. Soc. 91, 3497 (1969).

20 R. Köster, Angew. Chem. 71, 520 (1959).

21 K. A. Saegebarth. U.S. Pat. No. 3008997 (1961).

22 B. M. Mikhailov, A. Y. Bezmenov, L. S. Vasil'ev and V. G. Kiselev. Dokl. Akad. Nauk SSSR 155, 141 (1964).

23 L. I. Zakharkin and A. I. Kovredov. Zhur. Obshch. Khim. 36, 2153 (1966).

${ }^{24}$ H. C. Brown, E. Negishi and S. K. Gupta. J. Am. Chem. Soc. 92, 2460 (1970).

25 H. C. Brown, E. Negishi, and P. L. Burke. J. Am. Chem. Soc. 93, 3400 (1971).

${ }^{26}$ H. C. Brown, E. Negishi, and P. L. Burke. J. Am. Chem. Soc. 92, 6649 (1970).

27 H. C. Brown, E. Negishi, and P. L. Burke. Unpublished results.

28 H. C. Brown, E. Negishi, and P. L. Burke. Unpublished results.

29 E. F. Knights and H. C. Brown. J. Am. Chem. Soc. 90, 5280 (1968).

${ }^{30}$ Work in progress with P. L. Burke.

${ }^{31}$ H. C. Brown and G. J. Klender, Inorg. Chem. 1, 204 (1962).

32 H. C. Brown and A. W. Moerikofer, J. Am. Chem. Soc. 84, 1478 (1962).

${ }^{33}$ B. M. Mikhailov and V. A. Dorokhov. Dokl. Akad. Nauk SSSR 133, 119 (1960).

${ }^{34}$ M. F. Hawthorne. J. Am. Chem. Soc. 83, 2541 (1961).

35 T. A. Schegoleva, E. M. Shashkova, V. G. Kiselev and B. M. Mikhailov. Izv. Akad. Nauk SSSR, Ser. Khim. 365 (1964).

${ }^{36} \mathrm{H}$. C. Brown and E. Negishi. Unpublished results.

37 H. C. Brown and C. D. Pfaffenberger. J. Am. Chem. Soc. 89, 5475 (1967).

38 H. C. Brown, C. D. Pfaffenberger and P. L. Burke. Unpublished results.

${ }^{39}$ H. C. Brown, E. Negishi, and S. K. Gupta. J. Am. Chem. Soc. 92, 6648 (1970).

${ }^{40}$ Research in progress with Dr E. Negishi.

41 H. C. Brown and E. Negishi. J. Organometal. Chem. 26, C67 (1971).

${ }^{42}$ H. C. Brown and E. Negishi. J. Organometal. Chem. 28, C1 (1971).

43 H. C. Brown and E. Negishi. J. Am. Chem. Soc. 93, 3777 (1971).

44 R. Köster. Angew. Chem. Intern. Ed. Engl., 3, 174 (1964).

45 E. F. Knights and H. C. Brown. J. Am. Chem. Soc. 90, 5281 (1968).

46 H. C. Brown, E. F. Knights and R. A. Coleman. J. Am. Chem. Soc. 91.2144 (1969).

47 H. C. Brown and M. M. Rogić. J. Am. Chem. Soc. 91, 2146 (1969).

48 H. C. Brown, M. M. Rogić, H. Nambu and M. W. Rathke. J. Am. Chem. Soc. 91, 2147 (1969).

49 H. C. Brown and S. P. Rhodes. J. Am. Chem. Soc, 91, 2149 (1969). 